\title{
Educação Histórica: perspectivas de aprendizagem da história no ensino fundamental ${ }^{\star}$ \\ Historical Education: history learning perspectives in fundamental school
}

\author{
Marlene Cainelli ${ }^{* \star}$
}

\begin{abstract}
RESUMO
Este artigo tem por objetivo discutir o desenvolvimento parcial do projeto de pesquisa "Educação Histórica: iniciando crianças na arte do conhecimento histórico", que vem sendo realizado em uma escola particular, com alunos de oito anos que estão na segunda série do ensino fundamental. Pretende-se analisar os resultados da pesquisa empírica realizada no ano de 2005 . Tendo por base este estudo e também pesquisas realizadas em outros países apresentamos aqui reflexões sobre as perspectivas do ensino de história com crianças. Neste primeiro momento o trabalho com as crianças priorizou as narrativas, as relações com objetos no presente e no passado e o desenvolvimento das noções temporais.
\end{abstract}

Palavras-chave: Educação Histórica; Ensino; aprendizagem; Ensino de História.

\section{ABSTRACT}

The article shows the first results of research "Educação Histórica: iniciando crianças na arte do conhecimento". It has been developed in the private school in Londrina, Paraná (BR). The students attend the second year of elementary school. They are 08 years old. In this part of research was settled priority on narratives, the relationship with objetcs in the present and past and the development of the idea of time. Enclosed with the first results of this research and another research that have been done abroad, this paper shows some notes about teaching of history for children.

Key-words: Historical Education; Teaching; learning; History Teaching.

Com o fato de alguns colégios particulares dividirem em disciplinas os conteúdos da terceira e quarta série do ensino fundamental, substituindo o professor generalista formado em Pedagogia por professores com formação específica nas áreas de conhecimento, os alunos formados no curso de História começaram a enfrentar as salas de aulas de crianças de oito a dez anos. Em todos os anos de experiência profissional, meu trabalho voltou-se apenas para o ensino fundamental de quinta a oitava série e ensino médio. Todo o esforço de pensar metodologias para o ensino de História esteve centrado nessas séries escolares. Como professora de Metodologia do Ensino de História, deparei-me com o problema de explicar aos meus alunos como seria possível ensinar História para crianças de sete a dez anos.

No retorno da disciplina de História pós-ditadura militar, as investigações de aprendizagem ligadas ao pensamento piagetiano ${ }^{1}$, principalmente as generalizações dos estágios de desenvolvimento da criança, colocavam a impossibilidade de se ensinar conhecimentos abstratos para crianças em estágios ainda concretos de desenvolvimento cognitivo. Com isso a disciplina de História teve sua alocação restrita ao segundo ciclo do ensino fundamental, visto que para se aprender História seriam necessários níveis de abstração, os quais as crianças do ensino fundamental de primeiro ciclo ainda não dispunham.

Com novas pesquisas em meados da década de 1980, os estudos sobre ensino de História, principalmente no reino Unido e nos Estados Unidos da América, investigaram as 
possibilidades da construção do conhecimento em crianças. Bruner, Vygostsky entre outros recolocaram a discussão da capacidade ou incapacidade do estudo de História por crianças e adolescentes e os contextos mais propícios para que isso pudesse acontecer. (SOLE, 2004, p. 100).

A primeira grande questão que se colocava dizia respeito à possibilidade ou não de crianças, nas primeiras séries de alfabetização, aprenderem os conteúdos da disciplina História. É corrente afirmar-se que as crianças de sete a dez anos teriam dificuldades de aprendizagem da história devido a questões relacionadas ao conceito de tempo e espaço, o que dificultaria 0 entendimento das seqüências, durações e simultaneidade dos acontecimentos e, também, das localizações espaciais destes acontecimentos. Há ainda uma discussão sobre a característica abstrata dos conhecimentos históricos que dificultaria para a criança o entendimento de algo que teria de ser imaginado, pois não existe mais concretamente, ou seja, o passado.

Vários autores (COOPER, 1995; ASHBY e LEE, 1987; EGAN, 1994), a partir de pesquisas realizadas ao final do século $X X$, investigaram a possibilidade de crianças pequenas aprenderem História. Esses autores argumentam

que crianças destes níveis etários dispõem já de um conceito de causalidade, que se observa no seguimento coerente de uma narração; não será o conceito "formal" de causalidade, mas é já o narrativo que o ajudará a formalizar posteriormente o conceito de causalidade histórica. (SOLE, 2004, p. 100).

Segundo Hilary Cooper (2004, p. 59) crianças pequenas podem envolver- se ativamente em processos de pesquisa histórica:

... Ao aprender a interpretar a evidência, as crianças aprendem a fazer uma série de sugestões válidas acerca de como as coisas foram feitas ou utilizadas e, assim, concluir o que significavam para as pessoas que fizeram e usaram estes objetos.

Tendo como pressuposto as pesquisas de Cooper (2004) e Lee (1987), iniciei uma pesquisa empírica com crianças de oito anos em uma escola particular. No total, 14 crianças participaram da experiência que prevê em seu cronograma três fases de trabalho: a primeira fase com crianças de oito anos na segunda série do ensino fundamental; a segunda fase com as mesmas crianças na terceira série e finalmente, uma terceira fase com as crianças na quarta série. A escolha da segunda série deu-se pelo fato de que a escola já havia tentado incluir o estudo da História na segunda série em anos anteriores, sem obter bons resultados. Então, foi sugerido pela direção da escola que o trabalho se iniciasse pela segunda série para que fosse possível perceber as falhas dos projetos anteriores.

Iniciei os trabalhos com um grupo de quatro estagiários, tendo como ponto de partida as possíveis temáticas que seriam trabalhadas em sala de aula. Optou-se neste momento pela realização de um trabalho que permitisse descobrir o que as crianças entendiam por História e como reagiriam diante de um objeto do passado.

Para ensinar História, tinha-se como meta fugir do tradicional trabalho metodológico de iniciar a discussão pela história da criança; o ponto de partida era tentar entender o que a criança já sabia sobre o estatuto da História e quais suas percepções sobre conceitos chaves para a aprendizagem da disciplina. Também pareceu relevante entender como a criança pensava a História-disciplina e se tinha algum conhecimento sobre ela.

Nas pesquisas realizadas por Hilary Cooper, a autora afirma que crianças ao se relacionarem com objetos do passado estabelecem relações que as levam a imaginar o que os 
homens do passado sentiam e pensavam ao utilizar determinado objeto. Tomando como referência essa afirmação, optei por iniciar os trabalhos em sala de aula levando as crianças a pensarem sobre um determinado objeto do passado, no caso específico uma máquina de cortar macarrão. ${ }^{2}$

Foi permitido pela escola que nós realizássemos a pesquisa com as crianças em horário escolar durante duas horas por semana. Neste horário foi estipulado que as crianças teriam aulas de História.

Nosso primeiro contato foi tímido de ambas as partes, pois o estranhamento foi mútuo. Aos poucos as crianças perderam o receio de falar e começaram a expor suas idéias. A primeira pergunta que fiz para as crianças foi "O que é História?" e se elas sabiam o que se aprendia em História. Para tanto usei como exemplo as aulas de Português e Matemática. Entre as respostas, destacou-se a de que "A história começa quando a gente nasce", idéia com a qual todos os alunos concordaram. Dando como encerrada a discussão, tentei incentivá-los a pensar outras alternativas, obtendo respostas como: "Quando todos nascem" e "todo mundo tem uma história." É possível perceber que as crianças demonstram um entendimento da História a partir do nascimento e da existência de suas vidas. Vale salientar que essas crianças não tiveram ainda aulas sobre História, mas todas as crianças do ensino fundamental de primeira e segunda série já fizeram alguma atividade escolar envolvendo o registro de nascimento.

Pedi às crianças para que me contassem alguma história que conheciam. Meu objetivo era perceber como se processa o contar uma história, qual ênfase é dada aos personagens. Nesse momento todos se lembram de uma história que leram com a professora sobre uma rã. A história que contam quase coletivamente é marcada pela ação da rã. É uma história com lógica narrativa e discernimento, por parte das crianças, dos papéis desempenhados pelos personagens na construção da história que estão narrando.

A reprodução da história que ouviram da professora mostra a capacidade de organizar a narrativa do ponto de vista da ação dos personagens, além de uma percepção de valores revelados pelas atitudes dos personagens. Para Solé (2004, p.101)

\begin{abstract}
Ambas a narrativa e a história, são mais que uma coleção de fatos ou seqüência de acontecimentos. Estas envolvem a descrição e interpretação de causas que têm importância para os fatos. As suas investigações sugerem que a experiência se processa de modo narrativo e que a compreensão da história pelos alunos se realiza preferencialmente deste modo.
\end{abstract}

Assim, pode-se perceber que ao narrar a história aparecem valores e opiniões sobre a sociedade fictícia dos animais. O conhecimento prévio das crianças sobre os acontecimentos relatados e os valores do grupo social ao qual pertencem amarram-se na construção do novo conhecimento que estão desenvolvendo. Aparecem muito claros os conceitos de trabalho e responsabilidade, bastante enfatizados pelo grupo; dessa forma a narrativa possibilitou expressar os valores culturais do grupo e a troca de experiências de suas realidades, além de mapear lugares e temporalidades diversas.

Como a linha de investigação que orientou o trabalho tinha como objetivo perceber como a criança de oito anos entende conceitos históricos, o próximo passo foi investigar como a criança percebe o tempo, como identifica o antigo e como estabelece um contraponto com 0 novo. Também fez parte das discussões qual seria o entendimento da criança sobre temporalidade. Aqui o suporte para o trabalho com as crianças foram as pesquisas de Peter Lee. O autor afirma que para entender a História é preciso falar de situações concretas do passado e promover sua interpretação. (LEE, 2001). 
Para tanto, foi lançado aos alunos o desafio de descobrir a identidade e o tempo de existência de um objeto. A idéia de trabalhar com a observação de um objeto parte do pressuposto de que a observação direta de indícios do passado representado pelas fontes primárias faz com que o aluno, ao manusear o objeto, reflita sobre o passado ao qual este objeto pertenceu. Segundo Ribeiro (2004, p. 40), "o objecto sugere factos, processos e idéias e, dessa forma, potencia o conhecimento significativo de um determinado período históricocronológico". O procedimento tinha como objetivo levar os alunos a fazerem inferências sobre o passado, o que havia de diferente entre o objeto observado e hoje, além das referências possíveis ao cotidiano.

Também tinha como pressuposto fundamental e suporte para o trabalho as idéias de Ramos (2004, p. 32) sobre objeto gerador. Segundo o autor:

O objetivo primeiro do trabalho com objeto gerador é exatamente motivar reflexões sobre as tramas entre sujeito e objeto: perceber a vida dos objetos, entender e sentir que os objetos expressam traços culturais, que os objetos são criadores e criaturas do ser humano. Ora, tal exercício deve partir do próprio cotidiano, pois assim se estabelece o diálogo, o conhecimento do novo na experiência vivida: conversa entre o que se sabe e o que se vai saber - leitura dos objetos como ato de procurar novas leituras.

Tinha como objetivo criar um envolvimento das crianças com o objeto através da provocação de escolher algo que não estivesse presente no cotidiano de cada um, e estabelecer com isso um diálogo entre a história do objeto e a história de vida de cada criança.

Disse para eles que colocaria o objeto no centro da sala e que gostaria que eles respondessem em uma folha algumas perguntas sobre ele: O que é? Qual a idade? Para que serve? Quem usava? Você acha que ainda é utilizado? Você sabe como utilizá-lo? Coloquei no centro da sala uma máquina de cortar macarrão que data da década de 1950 para que observassem. Em momento algum identifiquei o objeto.

O contato com o objeto antigo fez que as crianças esboçassem várias reações, de espanto e desconhecimento, com expressões do tipo, "O que é isso?" "Que estranho!", mas principalmente enfatizaram que o objeto era muito velho, "Nossa é velho!" "Como é antigo!"

Perguntei a eles porque achavam o objeto muito velho. Seguindo as evidências apresentadas pelo objeto, as crianças responderam "que estava enferrujado", "que era uma máquina simples", "que parecia ser velho". Para a pergunta "o que é", alguns recorreram aos conhecimentos familiares para responder que se tratava "de um cilindro de pão", duas crianças apenas escreveram "máquina de fazer macarrão". Outros tiveram impressões diferentes e responderam: "ralador", "liquidificador", "secador de pano" e "fazedor de linha". Podemos perceber que ao identificarem o objeto como tendo várias utilidades, as crianças partiam das referências familiares, das aulas na escola e do olhar sobre o objeto. A lógica de definição da utilidade do objeto baseou-se nas possibilidades apresentadas pelas informações que tinham naquele momento.

Como haviam estudado sobre máquinas antigas, os alunos estabeleceram relações com as aulas anteriores e todos tinham certeza pelo mecanismo da máquina de macarrão que se tratava de uma máquina simples. As conclusões sobre para que serve variaram de acordo com as comparações com o presente. Ao pensar tratar de um secador de pano a criança estabeleceu uma relação de antiguidade possível para a máquina de secar roupa ou mesmo o ralador. Era perceptível que analisavam o mecanismo de funcionamento pensando nas semelhanças com os objetos nos dias de hoje. 
Depois de descobrirem o que era o objeto os alunos fizeram reflexões sobre questões do cotidiano como "quem usava?", "para que usava?" e "quando usava?". Para a primeira pergunta as respostas foram: "as pessoas, minha avó, meus avós, mulheres da cidade e mulheres do campo". Interroguei-os sobre os avós e porque achavam que os avós utilizavam o objeto. Quase por unanimidade responderam "porque naquele tempo só as mulheres trabalhavam em casa". A observação do objeto despertou nos alunos a possibilidade de pensar sobre o cotidiano do tempo das avós. Ao expressarem suas idéias sobre esse passado despertaram lembranças das avós cozinhando e dos avós trabalhando muito.

Levantei junto aos alunos a seguinte questão: "Por que não se faz mais macarrão com a máquina de macarrão?" A resposta foi "porque tem no supermercado", "porque meus pais não têm tempo", "porque minha mãe trabalha". Tentando levá-los ao desenvolvimento do pensamento histórico, procurei estabelecer com eles uma discussão sobre as diferenças cotidianas e sociais entre o tempo dos avós e o presente dos pais. Para tanto fiz algumas questões: "quem trabalhava na casa dos avós? onde moravam?", "quem trabalha na casa de vocês e onde vocês moram?", "havia supermercado na época dos avós?" A discussão possibilitou a percepção das diferenças entre as realidades dos avós e da casa deles. $O$ interesse dos alunos pela vida dos avós foi despertado pela manipulação e observação de um objeto que representava o cotidiano de um tempo reconhecido por eles como dos avós.

Assim como os historiadores fazem ao escreverem a História, fomos levantando os dados sobre o objeto observado. Primeiramente tentando descobrir o que era o objeto, depois qual a sua utilidade e quem o utilizava. Respondidas a essas questões, decidi descobrir com eles qual a idade do objeto.

Para a pergunta que "idade tem a máquina?", as respostas variaram de 10 até 700 anos. No entanto, a maioria ficou na casa dos 50 a 80 anos. A percepção mais contundente desta atividade foi observar que a questão temporal era respondida sem que os alunos estabelecessem uma relação entre o tempo presente e a contagem do tempo para o passado. Havia uma espécie de desprezo pelo tempo cronológico. Mesmo já tendo noções matemáticas sobre quantidade, a questão da medida temporal através dos anos era respondida rapidamente, de forma aleatória, sem nenhum tipo de reflexão. Então as respostas encaminharam-se para qualquer tempo que parecesse longo de 17 a 700 anos.

Muito se tem estudado sobre como as crianças trabalham questões temporais em aulas de História. Oliveira (2003) em pesquisa realizada com crianças de sete a dez anos sobre a concepção de tempo, utiliza-se do método clínico piagetiano como norteador de sua pesquisa, segundo suas conclusões, as crianças pensam o passado a partir do seu presente e não o contrário. Localizam os acontecimentos em um lugar atemporal apenas denominado enquanto passado, do mesmo modo que as crianças com que trabalhei quando falaram sobre a idade do objeto disseram de 17 a 700 anos. Não importa a data cronológica, mas a localização do objeto no passado e a percepção de que o objeto é de um tempo diferente do presente. De acordo com Oliveira (2003, p. 168):

No que se refere à noção de passado, percebemos que a criança analisa os acontecimentos através de sua lógica operatória.... Mesmo quando efetuam cálculos matemáticos, contradizem-se ao analisar esses resultados com relação ao tempo. Isto comprova a idéia de que o tempo histórico é uma construção causal e não meramente cronológica. Ou seja, o fato de a criança saber que seu avô ou bisavô tem setenta e dois anos e também saber que o descobrimento do Brasil ocorreu há 500 anos não impossibilita a elaboração da seguinte conclusão: meu avô ou bisavô viveu no tempo do descobrimento porque ele é muito velho. 
Diante das respostas das crianças e pensando com Oliveira, é possível analisar na perspectiva apontada por Elias para a questão da aprendizagem do tempo enquanto instituição com a qual a criança irá se familiarizar conforme a sociedade onde vive. Segundo Norbert Elias $(1998$, p.13)

O indivíduo não tem a capacidade de forjar, por si só, o conceito de tempo. Este, tal como a instituição que lhe é inseparável, vai sendo assimilado pela criança à medida que ela cresce numa sociedade em que ambas as coisas são tidas como evidentes. Numa sociedade assim, o conceito de tempo não é objeto de uma aprendizagem em sua simples qualidade de instrumento de uma reflexão destinada a encontrar seu resultado em tratados de filosofia; ao crescer, com efeito, toda criança vaise familiarizando com o tempo como um símbolo de uma instituição social cujo caráter coercitivo ela experimenta desde cedo.

A questão da temporalidade e da forma como as crianças entendem a passagem do tempo está relacionada com a experiência familiar. Recorrem a lembranças de objetos (presentes de Natal e aniversário), festas, nascimentos, para organizar o tempo com sentido de progressão. Um menino diz que se recorda de quando estava na barriga da mãe, de coisas que a mãe fazia. Segundo ele são suas lembranças mais antigas. Dessa forma, a criança atribui um primeiro sentido explicativo a um tempo em que ainda não existia fora da barriga da mãe. É uma forma de colocar-se no mundo. Recordando-se a partir de lembranças, na multiplicidade de tempos - passado, presente e futuro, a criança vai selecionando as memórias e construindo as dimensões temporais do real vivido e não vivido.

Depois da primeira atividade de observação do objeto, resolvi utilizar com as crianças a máquina de fazer macarrão. Preparando a massa e possibilitando às crianças o exercício prático de utilização de um objeto que para eles já não tinha utilidade. Perguntei a eles se o objeto era utilizado nos dias de hoje. A maioria respondeu que não, pois existem jeitos mais modernos de fazer macarrão, "comprando no supermercado".

Para iniciar a atividade no dia de fazer macarrão comecei com eles uma discussão sobre a origem do macarrão. Indaguei se eles sabiam de onde vinha o macarrão. Trabalhando na perspectiva do desenvolvimento da percepção sobre como a História é construída, estabeleci com as crianças a possibilidade de construírem hipóteses e conclusões sobre a origem do macarrão. Para minha surpresa a resposta que seria óbvia, não foi a Itália, e sim a China e o Japão. Segundo as conclusões dos alunos como os japoneses no Brasil comem muito macarrão, estes países seriam os que mais gostam de macarrão. Discutimos sobre a origem, sobre os molhos, os tipos de massa. O trabalho de fazer a massa do macarrão, cilindrar, cortar, esperar secar e depois cozinhar, permitiu aos alunos perceberem a relação de tempo necessária para esta atividade. Perceberam que demora, que a máquina é lenta e que o processo todo necessita de tempo.

Foi muito estimulante sentir o interesse em saber sobre a massa, o trigo, como o macarrão foi inventado, quem o descobriu. A aprendizagem sobre a diferença quanto à utilização do tempo entre as sociedades, a que fazia o macarrão e a que compra no supermercado envolveu as crianças em discussões acaloradas sobre o cotidiano dos avós e o dia-a-dia dos pais.

Segundo Cooper (2004, p. 57)

fazer inferências sobre as fontes, sobre quem as fez, porquê, como podem ter sido utilizadas e como afectaram a vida quotidiana do passado, pode levar o historiador a considerar como é que estas pessoas pensavam e o que sentiam. Desenvolver esta imaginação histórica, formulando uma vasta variedade de suposições, é fundamental para se interpretar o passado. 
Foi isso que fizemos, enquanto esticávamos a massa, cortávamos o macarrão. Imaginamos como as pessoas faziam a massa, como colocavam para secar, quem fazia, por que fazia ${ }^{3}$, quanto tempo levava, se faziam só isto, como inventaram a máquina de cortar elétrica e quem industrializou a massa. Várias foram as suposições e várias foram as discussões e críticas.

Essa atividade foi muito importante para o trabalho que estávamos realizando, permitiu que percebêssemos como as crianças utilizavam-se da imaginação histórica, como estabeleciam relações com seu presente para explicar o passado e de maneira exemplar como constróem valores a partir dos exemplos familiares.

Depois dessa experiência, ainda tendo Cooper (2004) como referência, levamos as crianças ao Museu Histórico, na perspectiva apresentada pela autora de que a criança aprende com experiências que tenham significado, com atividades que possibilitem a criança explorar e expor fora do ambiente escolar suas idéias e impressões. Também tinha como parâmetro continuar a reflexão de pensar sobre os objetos do cotidiano. Em nosso entendimento, o Museu poderia levar a criança a pensar sobre outros objetos que se modificaram com o tempo e objetos que deixaram de existir. A idéia era continuar com a leitura dos objetos, aprendendo a pensar historicamente através do conhecimento da história destes.

Diante da proposta de Ramos (2004, p. 24), articulamos as atividades de sala de aula com a visita ao museu:

com atividades vinculadas à 'historicidade dos objetos' na própria sala de aula, o professor incita a percepção dos alunos e aí eles terão o direito de saborear, com mais intensidade, as propostas de reflexão oferecidas pelo museu. Desse modo não se trata mais de "visitar o passado", e sim de animar estudos sobre o tempo pretérito, em relação com o que é vivido no presente.

O local escolhido foi o Museu Padre Carlos Weiss, Museu Histórico, como é conhecido, localizado no centro da cidade tendo uma arquitetura européia que o diferencia da maioria dos prédios da cidade. É, ainda, uma antiga estação ferroviária, ou seja, o próprio prédio/arquitetura é um objeto histórico. Dentro do museu as crianças, no primeiro momento da visita, ficaram a vontade para caminhar e escolher o que ver. Interessante notar que os alunos já esperavam esta visita. Ir ao Museu Histórico é para as crianças uma atividade natural da disciplina de História, pois ao avisar que iríamos ao museu, eles não demonstraram surpresa e disseram já esperar que isso fosse acontecer.

A primeira atitude das crianças ao serem deixadas livres no museu foi andar com certa desconfiança entre os objetos. O Museu Histórico tem uma organização que privilegia objetos dos primeiros moradores da cidade, como vestimentas, móveis, brinquedos, utensílios domésticos e de trabalho. Há também uma reprodução do interior de uma casa e cenários de alguns ofícios como barbeiro, dentista, alfaiate.

O Museu Histórico disponibiliza para as escolas um monitor ${ }^{4}$ que fala sobre a história de Londrina e a história do museu. Sobre a exposição e sobre como foi pensada a organização dos objetos não foi apresentada nenhuma justificativa. A visita monitorada foi um momento privilegiado para perceber a reação das crianças frente à história de Londrina narrada em fatos e datas. A primeira pergunta do monitor às crianças foi: "Londrina é nova ou antiga"? Os alunos responderam em conjunto: "antiga". A resposta dos alunos surpreendeu o monitor que ficou por alguns minutos em silêncio. Recuperado da surpresa o monitor reformulou a pergunta. "A idade de Londrina para uma cidade, indica que ela é nova ou velha?" Ao que os alunos responderam prontamente: "Velha". O monitor exasperou-se com a resposta, argumentando: "Como velha? Londrina tem só setenta anos." E os alunos: "Então é muito velha já tem setenta anos". Um dos alunos complementa: "Londrina tem a idade da minha avó, então é muito velha". Como o 
monitor não previu tal reação contrária ao seu discurso, apenas apresentou um argumento: "Para uma cidade, setenta anos é pouco tempo, Londrina é novíssima" - e continuou a explicação relatando fatos da cidade, para depois passar um vídeo sobre a história do município. Na conclusão das crianças a atividade poderia ser dispensada, pois tudo que o monitor falou estava no vídeo. Segundo suas opiniões, ou o vídeo ou o monitor, um dos dois é dispensável.

Ora, ao contrário do que parece, a atitude das crianças refletiu o fato de que a visita monitorada sugerida pelo museu não tem objetivos claros, peca por não levar o visitante a perceber a historicidade dos objetos e as relações da história ali colocada com suas próprias histórias. De acordo com Pessanha (1996, p. 37)

\begin{abstract}
...quando entramos nos museus, entramos no tribunal, onde várias falas se apresentam, várias vozes silenciosas, fortíssimas e eloqüentes se apresentam, há réplicas e tréplicas, há a possibilidade de o tempo todo de uma altercação, e tem-se, de alguma maneira, que tomar posição (...) para que ele (o público) seja levado a tentar tomar posição e ganhar essa autonomia de quem toma posição, que é o grande papel educativo que as instituições culturais podem ter, a própria instituição tem que assumir esse papel pedagógico, nesse sentido não totalitário, não autoritário, não monológico, e tem que abrir espaço para a dialogia, em todos os recursos possíveis.
\end{abstract}

O problema da forma de exposição do monitor foi à questão de pensar a narração da história de Londrina como única, cabendo ao vídeo apenas confirmar e dar legitimidade para as colocações já realizadas.

Foi solicitado às crianças depois de algum tempo passeando pelo museu que escrevessem o que mais havia chamado sua atenção. Os objetos que mais chamaram a atenção foram máquinas, por exemplo: máquinas de combustível, máquina de escrever, máquina de telefonista, máquina de fazer jornal, máquina de fazer café, máquina de fotografar. Também chamou a atenção a televisão da década de 1960, assim como os brinquedos, bonecas, carrinhos.

Os olhos e a atenção das crianças viram e observaram o que para eles naquele momento tinha significado e relacionava-se com algo ou de seu cotidiano ou que estavam aprendendo na escola. No caso sobre máquinas simples, como informou a professora ou os brinquedos e a televisão que fazem parte de seu dia-a-dia. No primeiro dia de atividades foi solicitado aos alunos que imaginassem o mundo sem energia elétrica, o que eles fariam depois da aula, sem poder assistir televisão ou jogar videogames. Das catorze crianças, doze desenharam-se dormindo.

Pedi a eles que justificas sem seus desenhos e eles responderam que sem televisão não teriam o que fazer e só poderiam passar o dia dormindo.

Foi solicitado às crianças que desenhassem aquilo que achavam ser mais antigo. Dos catorze alunos, seis desenharam a televisão, seis instrumentos variados (que tiveram suas formas modificadas com o tempo, por exemplo, máquina de fotografia, máquina de fazer café, máquina de escrever), uma desenhou uma boneca de porcelana. No meu entendimento ao desenharem objetos que permanecem nas suas vidas como a televisão, a máquina fotográfica, as crianças estabeleceram comparações com os objetos que têm em casa, compararam presente e passado, desenvolvendo as primeiras noções de historicidade.

Concordo com Ramos (2004, p. 35) quando este argumenta que entra em jogo a questão da História como campo de possibilidades, mudança que se expressa das mais 
variadas maneiras e que se torna visível na própria existência polivalente dos objetos em seu nascimento, sua morte e transformação.

Entre as conclusões a que posso chegar neste primeiro ato de reflexão sobre a pesquisa que venho realizando com crianças de oito a dez anos e as possibilidades do ensino de História, posso afirmar que as crianças constróem narrativas seguindo as experiências familiares e do grupo de convivência. Começam a elaborar conceitos relativos ao mundo onde vivem estabelecendo comparações entre as temporalidades e os espaços vividos e não vividos.

Há uma construção de sentidos para as explicações sobre o tempo e as mudanças temporais são explicadas a partir da percepção das transformações nos objetos e nas estruturas sociais a partir das suas vivências atuais. Observando a televisão de plasma e comparando-a com a televisão de fusível, a criança pode começar a estabelecer as primeiras noções de movimento do tempo e de transformações.

Mesmo que inicialmente estejam estas noções ligadas ao conceito de progresso é preciso desenvolver a noção de simultaneidade e transformação tendo como ponto de partida a percepção do aluno de que o tempo gerou a mudança e quais as implicações disso na sociedade. É preciso que o professor tenha condições de ensinar a pensar historicamente a partir do entendimento da criança dos múltiplos tempos e espaços que formam o tempo e o lugar em que ele está vivendo.

Ensinar História para crianças de oito anos significa pensar como despertar interesses pela contemporaneidade através do passado que a fundamenta. A questão principal é proporcionar à criança possibilidades de dialogar com o passado através das vozes e vestígios que o tempo multifacetado permite. É urgente que o professor do ensino fundamental pare de tentar levar o aluno para o passado, como se fosse possível embarcar em uma máquina do tempo. Cabe ao professor demonstrar aos alunos que conhecer o passado só é possível se conseguimos distinguir seus rostos, falas e sentimentos no presente.

\section{REFERÊNCIAS}

BARCA, I.; GAGO, M. Usos da narrativa em história. In: MELLO, M. do C.; LOPES, J. M. (Orgs.). Narrativas históricas e ficcionais: recepção e produção para professores e alunos. Actas do I Encontro Sobre Narrativas Históricas e Ficcionais: Portugal; Universidade do Minho, 2004. p. 29-40.

BARCA, I. Concepções de adolescentes sobre múltiplas explicações em história. In: (Org.). Perspectivas em educação histórica. Actas das Primeiras Jornadas Internacionais de Educação Histórica. Universidade do Minho, 2001. p. 29-44.

BARTHON, K. Qual a utilidade da história para crianças? Contributos do ensino de história para a cidadania. In: BARCA, I. (Org.). Para uma educação histórica de qualidade. Actas das IV Jornadas Internacionais de Educação Histórica.Universidade do Minho, 2004. p. 11-28.

CARRETERO, M.; VOSS, J. F. Aprender y pensar la historia. Buenos Aires: Amorrortu, 2004.

COOPER, H. O pensamento histórico das crianças. In: BARCA, I. (Org.). Para uma educação histórica de qualidade. Actas das IV Jornadas Internacionais de Educação Histórica. Universidade do Minho, 2004. p. 55-76.

ELIAS, N. Sobre o tempo. Rio de Janeiro: Jorge Zahar, 1998. 
LEE, P. Progressão da compreensão dos alunos em história. In: BARCA, I. (Org.). Perspectivas em educação histórica. Actas das Primeiras Jornadas Internacionais de Educação Histórica. Universidade do Minho, 2001. p. 13-29.

MIRANDA, S. R. Reflexões sobre a compreensão (incompreensões) do Tempo na escola. In: ZAMBONI, E. (Org.). Quanto tempo o tempo tem! Campinas: Alínea, 2003. p. 173-204.

OLIVEIRA, S. R. F. O tempo, a criança e o ensino de história. In: ZAMBONI, E. (Org.). Quanto tempo o tempo tem! Campinas: Alínea, 2003. p. 145-172.

RAMOS, F. R. L. A danação do objeto: o museu no ensino de história. Chapecó: Argos, 2004.

RIBEIRO, F. Exploração do pensamento arqueológico na aula de história. In: BARCA, I. (Org.). Para uma educação histórica de qualidade. Actas das IV Jornadas Internacionais de Educação Histórica. Universidade do Minho, 2004. p. 39-54.

SCHMIDT, M. A.; CAINELLI, M. Ensinar história. São Paulo: Scipione, 2004.

SOLE, M. G. P. S. Contributos do uso das lendas para a compreensão histórica: da teoria a prática. In: MELLO, M. do C.; LOPES, J. M. (Orgs.). Narrativas históricas e ficcionais: recepção e produção para professores e alunos. Actas do I Encontro Sobre Narrativas Históricas e Ficcionais. Portugal; Universidade do Minho, p. 99-130, 2004.

Texto recebido em 16 fev. 2005

Texto aprovado em 17 nov. 2005

\footnotetext{
* Este artigo constitui parte das reflexões do projeto de pesquisa "Educação histórica: iniciando crianças na arte da construção do conhecimento histórico", realizado no ano de 2005, na escola do Ensino Fundamental Ceca, Londrina/PR. O projeto iniciou-se em 2005, com término previsto para 2007.

** Doutora em História Social. Professora de Metodologia e Prática de Ensino e do Programa de Mestrado em Educação da Universidade Estadual de Londrina. Coordenadora do Laboratório de Ensino de História. Membro do Grupo de Pesquisa História e Ensino. E-mail: cainelli@uel.br.

${ }^{1}$ Aqui não interessa discutir as teorias piagetianas sobre os estágios de desenvolvimento mas sim a influência da utilização dessas teorias nas discussões curriculares.

${ }^{2}$ A máquina de cortar macarrão pertenceu ao pai de um amigo. A idade do objeto aproximadamente 60 anos.

${ }^{3} \mathrm{O}$ fato de um homem ser o cozinheiro naquele momento, levou as crianças a fazerem muitos questionamentos sobre quem cozinha hoje e antigamente. Foi possível discutir sobre relações sociais, diferenas sociais e de relacionamentos. Quero fazer um agradecimento ao professor Gilmar Arruda que se dispôs a cozinhar para as crianças e juntamente com este ofício exercer como sempre o ofício de historiador, levando as crianas a pensarem sobre a atividade que estavam fazendo do ponto de vista da história.

${ }^{4}$ Geralmente o monitor um estagiário do curso de história da Universidade Estadual de Londrina.
} 